\title{
PENERAPAN PRINSIP 5C DALAM KEBERHASILAN PENYALURAN KREDIT MODAL KERJA DI BANK UMUM PADA UKM DI KABUPATEN BANDUNG
}

\section{Application Of The 5c Principle In Distribution Of Working Capital In Commercial Banks In SMEs In Bandung District}

\author{
Palupi Permata Rahmi, Ezra Karamang \\ Sekolah Tinggi Ilmu Ekonomi Indonesia Membangun \\ Email:palupi.permata@inaba.ac.id1,ezra.karamang@inaba.ac.id ${ }^{2}$
}

\begin{abstract}
ABSTRAK
Penelitian ini bertujuan untuk mendeskripsikan persepsi nasabah terhadap penerapan prinsip 5C dalam keberhasilan penyaluran kredit modal kerja di Bank Umum Pada UKM di Kabupaten Bandung. Persepsi nasabah merupakan proses nasabah dalam memilih, mengelola dan menginterpretasikan informasi yang diterima dan selanjutnya akan dilakukan respons atas informasi tersebut. Prinsip 5C yaitu Character (Karakter/Watak), Capacity (Kapasitas), Capital (Modal), Collateral (Jaminan), Condition (Kondisi). Metode penelitian menggunakan metode kuantitatif dengan analisis deskritif. Pengukuran skala Likert yaitu untuk mendeskripsikan mengenai persepsi nasabah terhadap penerapan prinsip 5C dalam keberhasilan penyaluran kredit modal kerja di Bank Umum pada UKM di Kabupaten Bandung, sedangkan metode pengambilan sampel dengan cara purposive sampling yaitu teknik penentuan sampel dengan pertimbangan tertentu, yaitu sejumlah 50 UKM di Kabupaten Bandung yang telah menerima kredit modal kerja dari Bank Umum (Bank BRI). Analisis data yang digunakan adalah analisis deskriptif dan pengukuran skala Likert yaitu untuk mendeskripsikan mengenai persepsi nasabah terhadap penerapan prinsip 5C dalam keberhasilan penyaluran kredit modal kerja di Bank Umum pada UKM di kabupaten Bandung. Hasil penelitian menunjukan bahwa persepsi nasabah terhadap penerapan prinsip 5C dalam keberhasilan penyaluran kredit modal kerja di Bank Umum pada UKM di Kabupaten Bandung adalah mayoritas baik. Variabel keberhasilan penyaluran kredit modal kerja (Y) menunjukkan kriteria Baik, variabel Character (X1) menunjukkan kriteria Baik, variabel Capacity (X2) menunjukkan kriteria Baik, variabel Capital (X3) menunjukkan kriteria Baik, variabel Collateral (X4) menunjukkan kriteria Baik, dan variabel Condition (X5) menunjukkan kriteria Baik.
\end{abstract}

Kata Kunci : Character, Capacity, Capital, Collateral, Condition, UKM 


\begin{abstract}
ABSRACT
This study aims to describe the customer perceptions of the application of the 5C principle in the success of lending working capital loans at commercial banks of UKM in Bandung Regency. Customer perception is the customer's process in selecting, managing and interpreting information received and then a response will be made to that information. The 5C principles are Character, Capacity, Capital, Collateral, Condition. The research method uses quantitative methods with descriptive analysis. Likert scale measurement is to describe customer perceptions of the application of the 5C principle in the successful distribution of working capital loans in commercial banks to UKM in Bandung regency, while the sampling method by purposive sampling is a sampling technique with certain considerations, namely a number of 50 UKM in the Regency Bandung, which has received working capital loans from commercial banks (BRI Bank). Analysis of the data used is descriptive analysis and Likert scale measurement that is to describe the customer's perceptions of the application of the $5 \mathrm{C}$ principle in the success of working capital loans in Commercial Banks to UKM in Bandung regency. The results showed that customers' perceptions of the application of the $5 \mathrm{C}$ principle in the successful distribution of working capital loans at commercial banks to UKM in Bandung regency were good in majority. The success variable of working capital credit distribution $(Y)$ shows Good criteria, Character variable $\left(X_{1}\right)$ shows Good criteria, Capacity variable $\left(X_{2}\right)$ shows Good criteria, Capital variable $\left(X_{3}\right)$ shows Good criteria, Collateral variable $\left(X_{4}\right)$ shows Good criteria, and Condition variable $\left(\mathrm{X}_{5}\right)$ indicates Good criteria.
\end{abstract}

Keywords: Character, Capacity, Capital, Collateral, Condition, SMEs

\title{
PENDAHULUAN
}

Pertumbuhan dan perkembangan dunia usaha pada saat ini berlangsung dengan pesat. Sehingga bisa berdampak pada perusahaan yang bersaing semakin ketat. Setiap perusahaan akan mencoba berbagai strategi dan kebijakan agar dapat terus berkembang dan mempertahankannya. Oleh karena itu, dibutuhkan sebuah strategi, tetapi proses strategi tersebut dibutuhkan modal yang tidak sedikit. Terdapat berbagai cara untuk memenuhi kebutuhan modal, salah satu caranya adalah dengan cara meminjam pada lembaga keuangan yang merupakan pihak eksternal. Bank adalah Salah satu lembaga keuangan yang mempunyai peranan penting dalam mengatasi problema kebutuhan modal usaha.

Pengertian bank Menurut Undang-Undang RI No. 10 tahun 1998 “Bank yaitu badan usaha yang menghimpun dana dari masyarakat dalam bentuk simpanan dan menyalurkannya kepada masyarakat dalam bentuk kredit dan bentuk lainnya untuk meningkatkan taraf hidup rakyat banyak". Sedangkan menurut ensiklopedia dalam Firdaus dan Ariyanti (2008: 2) "Kredit adalah sistem keuangan untuk memudahkan pemindahan modal dari pemilik kepada pemakai 
dengan harapan mendapatkan laba". Menurut Fitriani (2012) Perbankan merupakan bagian yang sangat penting dalam perekonomian, salah satunya sebagai lembaga intermediasi yang tugasnya menghimpun dana dari masyarakat dan menyalurkannya kembali dalam bentuk kredit. Menurut data Bank Indonesia, bahwa dunia perbankan Indonesia sejak tahun 2008 menyalurkan Kredit Modal Kerja lebih banyak dibandingkan kredit yang lain (Kredit Konsumsi dan Investasi).

Kredit modal kerja adalah salah satu dari banyak produk kredit yang disalurkan di perbankan. Pengertian kredit modal kerja menurut Kasmir (2008: 77) “Kredit modal kerja merupakan kredit berjangka pendek yang diberikan oleh perbankan kepada pihak debitur untuk memenuhi kebutuhan modal kerjanya sehingga dapat meningkatkan dan memperlancar kinerja operasionalnya". Dalam melakukan proses pelaksanaan pemberian kredit diperlukan suatu proses pelaksanaan pemberian yang baik agar tidak terjadi kredit bermasalah. Beberapa hal yang perlu di survey oleh bank diantaranya : karakter, kapasitas, jaminan, hambatan, dan kondisi ekonomi atau yang lebih dikenal prinsip 5C (Character, Capacity, Capital, Collateral, Condition). Diperlukan suatu penelitian yang baik terhadap calon debitur mengenai kelayakan usaha atau besarnya pendapatan agar bank dapat terhindar atau menekan sekecil mungkin terjadinya risiko kredit bermasalah. Penerapan prinsip 5C dapat dilihat dari bagimana tanggapan respons nasabah terhadap penerapan prinsip 5C, yaitu character (karakter/watak), capacity (kapasitas), capital (modal), condition (kondisi), dan collateral (jaminan). Oleh karena itu penelitian ini ingin mengetahui dan mendeskripsikan penerapan prinsip 5C dalam keberhasilan penyaluran kredit modal kerja di Bank Umum pada UKM di Kabupaten Bandung.

\section{METODE PENELITIAN}

Metode yang digunakan dalam penelitian ini adalah metode deskriptif. Metode deskriptif digunakan untuk mendeskripsikan atau menguraikan permasalahan yang berkaitan dengan pertanyaan terhadap variabel. Metode analisis data yang digunakan adalah analisis deskriptif yaitu mendeskripsikan mengenai persepsi nasabah terhadap penerapan prinsip 5C dalam keberhasilan penyaluran kredit modal kerja di Bank Umum pada UKM di Kabupaten Bandung.

Metode pengambilan sampel dengan cara purposive sampling yaitu teknik penentuan sampel dengan pertimbangan tertentu. Dalam penelitian ini mengambil sampel atau responden sebanyak 50 responden. Data yang digunakan dalam penelitian ini adalah data primer dan data sekunder. Data primer yang digunakan adalah data yang diambil secara langsung melalui penyebaran kuesioner, hasil wawancara dan dokumentasi. Sedangkan untuk data sekunder yang digunakan dalam penelitian adalah data yang telah diolah oleh pihak lain 
meliputi informasi dari media elektronik (internet), literature dari perpustakaan serta hasil penelitian terdahulu.

\section{HASIL DAN PEMBAHASAN}

\section{Gambaran Umum Responden}

Responden dalam penelitian ini adalah nasabah PT. Bank Rakyat Indonesia (Persero) Tbk. Adapun profil responden yang telah mengisi kuesioner meliputi 4 aspek, yaitu profil berdasarkan jenis kelamin, usia, pendidikan terakhir, dan pendapatan per bulan.

\section{Berdasarkan Jenis Kelamin}

Gambaran mengenai jenis kelamin yang diambil dari responden saat mengisi pernyataan kuesioner adalah sebagai berikut:

Tabel 1. Responden Berdasarkan Jenis Kelamin

\begin{tabular}{|c|c|c|}
\hline \multirow{2}{*}{ Jenis Kelamin } & \multicolumn{2}{|c|}{ Jenis Kelamin } \\
\hline & Frekuensi & Persentase (\%) \\
\hline Laki-laki & 33 & 70 \\
\hline Perempuan & 17 & 30 \\
\hline Total & 50 & 100 \\
\hline
\end{tabular}

Sumber : Hasil kuesioner diolah (2019)

\section{Berdasarkan Usia}

Gambaran mengenai umur responden yang diteliti dapat dilihat pada tabel dibawah ini :

Tabel 2. Responden berdasarkan Usia

\begin{tabular}{|c|c|c|}
\hline Keterangan & Frekuensi & Persentase (\%) \\
\hline$<30$ Tahun & 7 & 12 \\
\hline 31-40 Tahun & 22 & 45 \\
\hline 41-50 Tahun & 17 & 35 \\
\hline >50 Tahun & 4 & 8 \\
\hline Total & 50 & 100 \\
\hline
\end{tabular}

Sumber : Hasil kuesioner diolah (2019)

\section{Berdasarkan Pendidikan terakhir}

Gambaran mengenai pendidikan terakhir responden saat mengisi pernyataan kuesioner adalah sebagai berikut : 
Tabel 3. Responden berdasarkan Pendidikan terakhir

\begin{tabular}{|c|c|c|}
\hline Keterangan & Frekuensi & Persentase $(\%)$ \\
\hline SD & 5 & 10 \\
\hline SMP & 12 & 20 \\
\hline SMA & 30 & 65 \\
\hline Perguruan Tinggi & 3 & 5 \\
\hline Total & 50 & 100 \\
\hline
\end{tabular}

Sumber : Hasil kuesioner diolah (2019)

\section{Berdasarkan Pendapatan per Bulan}

Gambaran mengenai pendapatan per bulan responden saat mengisi pernyataan kuesioner adalah sebagai berikut :

Tabel 4. Responden berdasarkan Pendapatan/bulan

\begin{tabular}{lcc}
\hline \multicolumn{1}{c}{ Keterangan } & Frekuensi & Persentase (\%) \\
\hline$<5.000 .000$ & 11 & 30 \\
$5.000 .000-10.000 .000$ & 25 & 50 \\
$10.000 .000-15.000 .000$ & 9 & 10 \\
$15.000 .000-20.000 .000$ & 3 & 6 \\
$>20.000 .000$ & 2 & 4 \\
\hline Total & $\mathbf{5 0}$ & $\mathbf{1 0 0}$
\end{tabular}

Sumber : Hasil kuesioner diolah (2019)

Hasil Pengujian Instrumen

Hasil Uji Validitas Variabel Y

Tabel 5. Hasil Uji Validitas Variabel Y (Keberhasilan penyaluran kredit modal kerja)

\begin{tabular}{cccc}
\hline Item & Nilai r Hitung & Nilai r Tabel & Keterangan \\
\hline 1 & 0,731 & 0,294 & Valid \\
2 & 0,706 & 0,294 & Valid \\
3 & 0,667 & 0,294 & Valid \\
4 & 0,719 & 0,294 & Valid \\
5 & 0,655 & 0,294 & Valid \\
6 & 0,442 & 0,294 & Valid \\
7 & 0,603 & 0,294 & Valid \\
8 & 0,664 & 0,294 & Valid \\
9 & 0,784 & 0,294 & Valid \\
10 & 0,725 & 0,294 & Valid
\end{tabular}

Sumber : Data Primer yang Diolah

Berdasarkan Tabel 5, menunjukkan bahwa semua pernyataan nilai corrected item total correlation memiliki nilai yang lebih besar 0,294 sehingga dapat dikatakan semua pernyataan valid. 


\section{Hasil Uji Validitas Variabel X}

Penelitian ini menggunakan variabel $\mathrm{X}$ sebagai variabel independen yaitu Character (X1), Capacity (X2), Capital (X3), Collateral (X4), dan Condition (X5).

Tabel 6. Hasil Uji Validitas Variabel $X_{1}$ (Character)

\begin{tabular}{cccc}
\hline Item & Nilai r Hitung & Nilai r Tabel & Keterangan \\
\hline 1 & 0,770 & 0,294 & Valid \\
2 & 0,843 & 0,294 & Valid \\
3 & 0,724 & 0,294 & Valid \\
4 & 0,805 & 0,294 & Valid \\
5 & 0,729 & 0,294 & Valid \\
\hline
\end{tabular}

Sumber : Data Primer yang Diolah

Berdasarkan Tabel 6, menunjukkan bahwa semua pernyataan nilai corrected item total correlation memiliki nilai yang lebih besar 0,294 sehingga dapat dikatakan semua pernyataan valid.

Tabel 7. Hasil Uji Validitas Variabel $X_{2}$ (Capacity)

\begin{tabular}{cccc}
\hline Item & Nilai r Hitung & Nilai r Tabel & Keterangan \\
\hline 1 & 0,797 & 0,294 & Valid \\
2 & 0,788 & 0,294 & Valid \\
3 & 0,806 & 0,294 & Valid \\
4 & 0,868 & 0,294 & Valid \\
5 & 0,533 & 0,294 & Valid \\
\hline
\end{tabular}

Sumber: Data Primer yang Diolah

Berdasarkan tabel 7, diatas menunjukkan bahwa semua pernyataan nilai corrected item total correlation memiliki nilai yang lebih besar 0.294 sehingga dapat dikatakan semua pernyataan valid.

Tabel 8. Hasil Uji Validitas Variabel $X_{3}$ (Capital)

\begin{tabular}{cccc}
\hline Item & Nilai r Hitung & Nilai r Tabel & Keterangan \\
\hline 1 & 0,737 & 0,294 & Valid \\
2 & 0,805 & 0,294 & Valid \\
3 & 0,796 & 0,294 & Valid \\
4 & 0,660 & 0,294 & Valid \\
5 & 0,697 & 0,294 & Valid \\
\hline
\end{tabular}

Sumber : Data Primer yang Diolah

Berdasarkan Tabel 8, menunjukkan bahwa semua pernyataan nilai corrected item total correlation memiliki nilai yang lebih besar 0,294 sehingga dapat dikatakan semua pernyataan valid. 
Tabel 9. Hasil Uji Validitas Variabel $X_{4}$ (Collateral)

\begin{tabular}{cccc}
\hline Item & Nilai r Hitung & Nilai r Tabel & Keterangan \\
\hline 1 & 0,505 & 0,294 & Valid \\
2 & 0,431 & 0,294 & Valid \\
3 & 0,686 & 0,294 & Valid \\
4 & 0,538 & 0,294 & Valid \\
5 & 0,773 & 0,294 & Valid \\
\hline
\end{tabular}

Sumber : Data Primer yang Diolah

Berdasarkan Tabel 9, menunjukkan bahwa semua pernyataan nilai corrected item total correlation memiliki nilai yang lebih besar 0,294 sehingga dapat dikatakan semua pernyataan valid.

Tabel 10. Hasil Uji Validitas Variabel $\mathrm{X}_{5}$ (Condition)

\begin{tabular}{cccc}
\hline Item & Nilai $\mathbf{r}$ Hitung & Nilai r Tabel & Keterangan \\
\hline 1 & 0,706 & 0,294 & Valid \\
2 & 0,785 & 0,294 & Valid \\
3 & 0,785 & 0,294 & Valid \\
4 & 0,601 & 0,294 & Valid \\
5 & 0,649 & 0,294 & Valid \\
\hline
\end{tabular}

Sumber : Data Primer Yang Diolah

Berdasarkan Tabel 10, menunjukkan bahwa semua pernyataan nilai corrected item total correlation memiliki nilai yang lebih besar 0,294 sehingga dapat dikatakan semua pernyataan valid.

\section{Hasil Uji Reliabilitas}

Setelah dilakukan uji validitas, langkah selanjutnya adalah uji reliabilitas. Reliabilitas dianggap sebagai suatu instrumen yang dapat kurang dipercaya untuk digunakan sebagai alat pengumpul data karena instrumen tersebut sudah baik. Suatu uji instrumen dikatakan reliabel manakala memenuhi standar koefisien Cronbach alpha lebih besar atau sama dengan 0,60 ( $\alpha \geq 0,60)$.

Tabel 11. Hasil Uji Reliabilitas Variabel Y (Keberhasilan Penyaluran Kredit Modal Kerja) Reliability Statistics

\begin{tabular}{cc}
\hline Cronbach's Alpha & N of Items \\
\hline, 858 & 10 \\
\hline
\end{tabular}

Sumber: Data Primer yang Diolah

Berdasarkan Tabel diatas, dapat disimpulkan bahwa variabel (Keberhasilan Penyaluran Kredit Modal Kerja) dinyatakan reliabel, karena r hitung 0,858 $\geq 0,60$. 
Tabel 12. Hasil Uji Reliabilitass Variabel $X_{1}$ (Character) Reliability Statistics

\begin{tabular}{cc}
\hline Cronbach's Alpha & N of Items \\
\hline, 823 & 5 \\
\hline
\end{tabular}

Sumber : Data Primer Yang Diolah

Berdasarkan Tabel diatas, dapat disimpulkan bahwa variabel $\mathrm{X}_{1}$ (Character) dinyatakan reliabel, karena $r$ hitung $0,823 \geq 0,60$.

Tabel 13. Hasil Uji Reliabilitas Variabel $\mathrm{X}_{2}$ (Capacity) Reliability Statistics

\begin{tabular}{cc}
\hline Cronbach's Alpha & N of Items \\
\hline, 819 & 5
\end{tabular}

Sumber : Data Primer yang Diolah

Berdasarkan Tabel diatas, dapat disimpulkan bahwa variabel $\mathrm{X}_{2}$ (Capacity) dinyatakan reliabel, karena r hitung $0,819 \geq 0,60$.

Tabel 14. Hasil Uji Reliabilitas Variabel $X_{3}$ (Capital) Reliability Statistics

\begin{tabular}{cc}
\hline Cronbach's Alpha & N of Items \\
\hline, 793 & 5 \\
\hline
\end{tabular}

Sumber : Data Primer yang Diolah

Berdasarkan Tabel diatas, dapat disimpulkan bahwa variabel $\mathrm{X}_{3}$ (Capital) dinyatakan reliabel, karena $\mathrm{r}$ hitung $0,793 \geq 0,60$.

Tabel 15. Hasil Uji Reliabilitas Variabel X4 (Collateral) Reliability Statistics

\begin{tabular}{cc}
\hline Cronbach's Alpha & N of Items \\
\hline, 710 & 5 \\
\hline
\end{tabular}

Sumber : Data Primer yang Diolah

Berdasarkan Tabel diatas, dapat disimpulkan bahwa variabel $\mathrm{X}_{4}$ (Collateral) dinyatakan reliabel, karena $\mathrm{r}$ hitung $0,710 \geq 0,60$.

Tabel 16. Hasil Uji Reliabilitas Variabel X5 (Condition) Reliability Statistics

\begin{tabular}{cc}
\hline Cronbach's Alpha & N of Items \\
\hline, 749 & 5 \\
\hline
\end{tabular}

Sumber : Data Primer yang Diolah

Berdasarkan Tabel diatas, dapat disimpulkan bahwa variabel $\mathrm{X}_{5}$ (Condition) dinyatakan reliabel, karena $\mathrm{r}$ hitung $0,749 \geq 0,60$. Berdasarkan hasil uji reliabilitas yang dilakukan terhadap semua item dalam penelitian ini menunjukkan bahwa semua item penelitian dapat dikatakan reliabel (Nilai koefisien reliabilitas lebih besar dari 0,60) dengan demikian tetap dapat digunakan sebagai instrumen dalam mengukur variabel yang ditetapkan dalam penelitian ini. 


\section{Analisis Deskriptif Tanggapan Responden}

Responden dalam penelitian ini adalah nasabah PT. Bank Rakyat Indonesia (Persero) Tbk. Sesuai dengan metode yang telah ditentukan sebelumnya, maka skala yang digunakan untuk pembobotan item kuesioner variabel $X$ adalah skala likert. Persepsi responden mengenai Character $\left(X_{1}\right)$, Capacity $\left(X_{2}\right)$, Capital $\left(X_{3}\right)$, Collateral $\left(X_{4}\right)$, dan Conditions $\left(X_{5}\right)$. dan variabel $Y$ Keberhasilan Penyaluran Kredit Modal Kerja dapat diuraikan sebagai berikut :

\section{Tanggapan Responden Mengenai Keberhasilan Penyaluran Kredit Modal Kerja (Variabel Y)}

Berdasarkan hasil dari instrumen yang disebarkan kepada 50 responden, maka hasil pengolahan data mengenai Keberhasilan Penyaluran Kredit Modal Kerja (Variabel Y) seperti ditunjukkan pada tabel berikut ini.

Tabel 17. Analisis Pernyataan Responden Mengenai Keberhasilan Penyaluran Kredit Modal Kerja (Variabel Y)

\begin{tabular}{ccccccc}
\hline \multirow{5}{*}{ Item Pernyataan } & \multicolumn{5}{c}{ Frekuensi } & \multirow{2}{*}{$\begin{array}{c}\text { Total } \\
\text { Skor }\end{array}$} \\
\cline { 2 - 5 } & SS (5) & S (4) & N (3) & TS (2) & STS (1) & \\
\hline Y1 & 6 & 36 & 8 & 0 & 0 & $\mathbf{1 9 8}$ \\
Y2 & 7 & 35 & 8 & 0 & 0 & $\mathbf{1 9 9}$ \\
Y3 & 12 & 28 & 10 & 0 & 0 & $\mathbf{1 7 2}$ \\
Y4 & 11 & 29 & 9 & 1 & 0 & $\mathbf{2 0 0}$ \\
Y5 & 3 & 35 & 12 & 0 & 0 & $\mathbf{1 9 1}$ \\
Y6 & 5 & 33 & 12 & 0 & 0 & $\mathbf{1 9 3}$ \\
Y7 & 1 & 35 & 13 & 1 & 0 & $\mathbf{1 8 6}$ \\
Y8 & 3 & 32 & 13 & 2 & 0 & $\mathbf{1 8 6}$ \\
Y9 & 2 & 39 & 9 & 0 & 0 & $\mathbf{1 9 3}$ \\
Y10 & 5 & 36 & 9 & 0 & 0 & $\mathbf{1 9 6}$ \\
\hline \multicolumn{7}{c}{ Jumlah Total Skor } \\
\hline \multicolumn{7}{c}{ Rata - Rata (Mean) }
\end{tabular}

Sumber: Data Kuesioner yang Diolah (2019)

Berdasarkan tabel di atas dapat dilihat gambaran Keberhasilan Penyaluran Kredit Modal Kerja yang diwakili oleh 10 indikator, skor tertinggi yang diperoleh sebesar 200 terdapat pada indikator Bank BRI Melakukan Analisis Capital Terhadap Calon Debitur Sebelum Kredit Diberikan, sedangkan skor terendah sebesar 172 terdapat pada indikator Bank BRI Melakukan Analisis Capacity Terhadap Calon Debitur Sebelum Kredit Diberikan. Dari tabel tanggapan responden diatas, diperoleh angka penafsiran 191,4 berdasarkan skala interval yang sudah ditentukan maka angka tersebut menunjukkan kriteria Baik karena berada pada rentang 179,4 - 217,3. 


\section{Tanggapan Responden Mengenai Character (Variabel $\mathbf{X}_{\mathbf{1}}$ )}

Berdasarkan hasil dari instrumen yang disebarkan kepada 50 responden, maka hasil pengolahan data mengenai Character $\left(\right.$ Variabel $\mathrm{X}_{1}$ ) seperti ditunjukkan pada tabel berikut ini :

Tabel 18. Analisis Pernyataan Responden Mengenai Character (Variabel $X_{1}$ )

\begin{tabular}{ccccccc}
\hline \multirow{2}{*}{ Item pernyataan } & \multicolumn{5}{c}{ Frekuensi } & $\begin{array}{c}\text { Total } \\
\text { Skor }\end{array}$ \\
\cline { 2 - 6 } & SS (5) & S (4) & N (3) & TS (2) & STS (1) & $\mathbf{1 9 4}$ \\
X1.1 & 4 & 37 & 8 & 1 & 0 & $\mathbf{1 8 4}$ \\
X1.2 & 3 & 29 & 17 & 1 & 0 & $\mathbf{2 1 4}$ \\
X1.3 & 1 & 36 & 21 & 1 & 0 & $\mathbf{2 1 7}$ \\
X1.4 & 1 & 26 & 22 & 1 & 0 & $\mathbf{1 8 4}$ \\
X1.5 & 3 & 30 & 15 & 2 & 0 & $\mathbf{9 9 3}$ \\
\hline \multicolumn{7}{c}{ Jumlah Total Skor } \\
\hline
\end{tabular}

Sumber: Data Kuesioner yang Diolah (2019)

Berdasarkan tabel di atas dapat dilihat gambaran Character yang diwakili oleh 5 indikator, skor tertinggi yang diperoleh sebesar 217 terdapat pada indikator Saya akan mendahulukan melunasi kredit dari pada kebutuhan lainnya, sedangkan skor terendah sebesar 184 terdapat pada indikator Saya memiliki pergaulan yang baik dengan masyarakat, Dari tabel tanggapan responden diatas, diperoleh angka penafsiran 198,6 berdasarkan skala interval yang sudah ditentukan maka angka tersebut menunjukkan kriteria Baik karena berada pada rentang 179,4 - 217,3.

\section{Tanggapan Responden Mengenai Capacity (Variabel $\mathrm{X}_{2}$ )}

Berdasarkan hasil dari instrumen yang disebarkan kepada 50 responden, maka hasil pengolahan data mengenai Capacity (Variabel $\mathrm{X}_{2}$ ) seperti ditunjukkan pada tabel berikut ini.

Tabel 19. Analisis Pernyataan Responden Mengenai Capacity (Variabel $X_{2}$ )

\begin{tabular}{ccccccc}
\hline \multirow{2}{*}{ Item pernyataan } & \multicolumn{5}{c}{ Frekuensi } & $\begin{array}{c}\text { Total } \\
\text { Skor }\end{array}$ \\
\cline { 2 - 6 } & SS (5) & $\mathbf{S ~ ( 4 )}$ & $\mathbf{N ~ ( 3 )}$ & TS (2) & STS (1) & $\mathbf{1 9 8}$ \\
X2.1 & 6 & 36 & 8 & 0 & 0 & $\mathbf{1 9 9}$ \\
X2.2 & 7 & 35 & 8 & 0 & 0 & $\mathbf{2 0 2}$ \\
X2.3 & 12 & 28 & 10 & 0 & 0 & $\mathbf{2 0 0}$ \\
X2.4 & 11 & 29 & 9 & 1 & 0 & $\mathbf{1 9 1}$ \\
X2.5 & 3 & 35 & 12 & 0 & 0 & $\mathbf{9 9 0}$ \\
\hline \multicolumn{7}{c}{ Jumlah Total Skor } \\
\hline
\end{tabular}

Sumber: Data Kuesioner yang Diolah (2019) 
Berdasarkan tabel di atas dapat dilihat gambaran Capacity yang diwakili oleh 5 indikator, skor tertinggi yang diperoleh sebesar 202 terdapat pada indikator Dalam mengangsur kredit, Saya menyisihkan sebagian dari penghasilan yang diperoleh, sedangkan skor terendah sebesar 191 terdapat pada indikator Saya mempunyai pendapatan yang relatif meningkat, Dari tabel tanggapan responden diatas, diperoleh angka penafsiran 198, berdasarkan skala interval yang sudah ditentukan maka angka tersebut menunjukkan kriteria Baik karena berada pada rentang 179,4 - 217,3.

\section{Tanggapan Responden Mengenai Capital (Variabel $X_{3}$ )}

Berdasarkan hasil dari instrumen yang disebarkan kepada 50 responden, maka hasil pengolahan data mengenai Capital (Variabel $\mathrm{X}_{3}$ ) seperti ditunjukkan pada tabel berikut ini.

Tabel 20. Analisis Pernyataan Responden Mengenai Capital (Variabel $X_{3}$ )

\begin{tabular}{ccccccc}
\hline \multirow{2}{*}{ Item Pernyataan } & \multicolumn{7}{c}{ Frekuensi } & $\begin{array}{c}\text { Total } \\
\text { Skor }\end{array}$ \\
\cline { 2 - 6 } & SS (5) & S (4) & N (3) & TS (2) & STS (1) & $\mathbf{1 9 3}$ \\
X3.1 & 5 & 33 & 12 & 0 & 0 & $\mathbf{1 7 3}$ \\
X3.2 & 1 & 35 & 13 & 1 & 0 & $\mathbf{1 8 6}$ \\
X3.3 & 3 & 32 & 13 & 2 & 0 & $\mathbf{1 9 6}$ \\
X3.4 & 5 & 36 & 9 & 0 & 0 & $\mathbf{1 9 6}$ \\
X3.5 & 5 & 36 & 9 & 0 & 0 & $\mathbf{9 4 4}$ \\
\hline \multicolumn{7}{c}{ Jumlah Total Skor } \\
\hline
\end{tabular}

Sumber: Data Kuesioner yang Diolah (2019)

Berdasarkan tabel di atas dapat dilihat gambaran Capital yang diwakili oleh 5 indikator, skor tertinggi yang diperoleh sebesar 196 terdapat pada indikator Saya memiliki modal dalam usaha UKM, sedangkan skor terendah sebesar 173 terdapat pada indikator Saya memiliki pekerjaan yang tetap selain bidang usaha UKM, Dari tabel tanggapan responden diatas, diperoleh angka penafsiran 188,8 berdasarkan skala interval yang sudah ditentukan maka angka tersebut menunjukkan kriteria Baik karena berada pada rentang 179,4 - 217,3.

\section{Tanggapan Responden Mengenai Collateral (Variabel $\mathbf{X}_{4}$ )}

Berdasarkan hasil dari instrumen yang disebarkan kepada 50 responden, maka hasil pengolahan data mengenai Collateral (Variabel $\mathrm{X}_{4}$ ) seperti ditunjukkan pada tabel berikut ini. 
Tabel 21. Analisis Pernyataan Responden Mengenai Collateral (Variabel $\mathrm{X}_{4}$ )

\begin{tabular}{ccccccc}
\hline \multirow{2}{*}{ Item pernyataan } & \multicolumn{7}{c}{ Frekuensi } & Total \\
\cline { 2 - 6 } & SS (5) & S (4) & N (3) & TS (2) & STS (1) & Skor \\
\hline X4.1 & 6 & 33 & 11 & 0 & 0 & $\mathbf{1 9 5}$ \\
X4.2 & 5 & 33 & 12 & 0 & 0 & $\mathbf{1 9 3}$ \\
X4.3 & 1 & 37 & 11 & 1 & 0 & $\mathbf{1 8 8}$ \\
X4.4 & 1 & 38 & 11 & 0 & 0 & $\mathbf{1 9 0}$ \\
X4.5 & 4 & 39 & 6 & 1 & 0 & $\mathbf{1 9 6}$ \\
\hline \multicolumn{7}{c}{ Jumlah Total Skor } \\
\hline
\end{tabular}

Sumber: Data Kuesioner yang telah diolah (2019)

Berdasarkan tabel di atas dapat dilihat gambaran Collateral yang diwakili oleh 5 indikator, skor tertinggi yang diperoleh sebesar 196 terdapat pada indikator Saya mampu melengkapi persyaratan pinjaman secara lengkap dengan dokumen asli, sedangkan skor terendah sebesar 188 terdapat pada indikator Kredit dapat cair setelah agunan saya dinilai oleh pihak Bank, Dari tabel tanggapan responden diatas, diperoleh angka penafsiran 192,4 berdasarkan skala interval yang sudah ditentukan maka angka tersebut menunjukkan kriteria Baik karena berada pada rentang 179,4 - 217,3.

\section{Tanggapan Responden Mengenai Condition (Variabel $\mathrm{X}_{5}$ )}

Berdasarkan hasil dari instrumen yang disebarkan kepada 50 responden, maka hasil pengolahan data mengenai Condition (Variabel $\mathrm{X}_{5}$ ) seperti ditunjukkan pada tabel berikut ini.

Tabel 22. Analisis Pernyataan Responden Mengenai Condition (Variabel $X_{5}$ )

\begin{tabular}{ccccccc}
\hline \multirow{2}{*}{ Item pernyataan } & \multicolumn{7}{c}{ Frekuensi } & Total \\
\cline { 2 - 6 } & SS (5) & S (4) & N (3) & TS (2) & STS (1) & Skor \\
\hline X5.1 & 5 & 33 & 12 & 0 & 0 & $\mathbf{1 9 3}$ \\
X5.2 & 1 & 35 & 13 & 1 & 0 & $\mathbf{1 8 6}$ \\
X5.3 & 3 & 32 & 13 & 2 & 0 & $\mathbf{1 9 4}$ \\
X5.4 & 6 & 36 & 8 & 0 & 0 & $\mathbf{1 9 8}$ \\
X5.5 & 7 & 35 & 8 & 0 & 0 & $\mathbf{1 9 9}$ \\
\hline \multicolumn{7}{c}{ Jumlah Total Skor } \\
\hline
\end{tabular}

Sumber: Data Kuesioner yang telah diolah (2019)

Berdasarkan tabel di atas dapat dilihat gambaran Condition yang diwakili oleh 5 indikator, skor tertinggi yang diperoleh sebesar 199 terdapat pada indikator Selama mendapat pinjaman dari pihak bank BRI, saya pernah mengalami musibah yang mengakibatkan pekerjaan terganggu, sedangkan skor terendah sebesar 186 terdapat pada indikator perkembangan bidang usaha dan bisnis saya saat ini sedang mengalami kemajuan, diperoleh angka penafsiran 194, berdasarkan skala 
interval yang sudah ditentukan maka angka tersebut menunjukkan kriteria Baik karena berada pada rentang 179,4 - 217,3.

\section{KESIMPULAN DAN REKOMENDASI KEBIJAKAN}

\section{Kesimpulan}

Berdasarkan hasil penelitian dan pembahasan Mengenai Penerapan Prinsip 5c Dalam Penyaluran Kredit Modal Kerja Di Bank Umum Pada UKM maka dapat disimpulkan sebagai berikut :

1. Variabel keberhasilan penyaluran kredit modal kerja (Y) diperoleh angka penafsiran rata-rata 191,4 berdasarkan skala interval yang sudah ditentukan maka angka tersebut menunjukkan kriteria Baik karena berada pada rentang 179,4 - 217,3.

2. Variabel Character $\left(X_{1}\right)$ diperoleh angka penafsiran rata-rata 198,6 berdasarkan skala interval yang sudah ditentukan maka angka tersebut menunjukkan kriteria Baik karena berada pada rentang 179,4 - 217,3.

3. Variabel Capacity $\left(X_{2}\right)$ diperoleh angka penafsiran rata-rata 198, berdasarkan skala interval yang sudah ditentukan maka angka tersebut menunjukkan kriteria Baik karena berada pada rentang 179,4 - 217,3.

4. Variabel Capital $\left(X_{3}\right)$ diperoleh angka penafsiran rata-rata 188,8 berdasarkan skala interval yang sudah ditentukan maka angka tersebut menunjukkan kriteria Baik karena berada pada rentang 179,4 - 217,3.

5. Variabel Collateral $\left(\mathrm{X}_{4}\right)$ Dari tabel tanggapan responden diatas, diperoleh angka penafsiran rata-rata 192,4 berdasarkan skala interval yang sudah ditentukan maka angka tersebut menunjukkan kriteria Baik karena berada pada rentang 179,4 - 217,3.

6. Variabel Condition (X) diperoleh angka penafsiran 194, berdasarkan skala interval yang sudah ditentukan maka angka tersebut menunjukkan kriteria Baik karena berada pada rentang 179,4 - 217,3.

\section{Rekomendasi Kebijakan}

1. Dalam penyaluran kredit modal kerja tetap konsisten menggunakan prinsip-prinsip penyaluran kredit (5C).

2. Evaluasi penyaluran kredit modal kerja secara menyeluruh dan berkesinambungan perlu dilakukan untuk menghindari terjadinya kredit macet. 


\section{DAFTAR PUSTAKA}

Bank Indonesia. 1998. UU No.10 tahun 1998, Tentang Perubahan Terhadap UU No. 7 tahun 1992, Jakarta

Firdaus, Rahmat, dan Maya Ariyanti. 2008. Manajemen perkreditan Bank Umum: Teori, masalah Kebijakan dan Aplikasinya. Bandung: Alfabeta

Fitriani, D., 2012. Pengaruh Ratio Keuangan Bank Terhadap Penyaluran Kredit Modal Kerja. Skripsi Fakultas Ekonomi Universitas Andalas.

Kasmir. 2008. Bank dan Lembaga Keuangan Lainnya. Jakarta: PT Raja Grafindo Persada 